Andrew D. Maslow MD, Terrance W. Breen MD, Mukesh C. Sarna MD, Anil K. Soni MD, James Watkins MD, Nancy E. Oriol MD

\title{
Prevalence of coagu- lation abnormalities associated with intrauterine fetal death
}

Purpose: The purpose of this study was to determine factors associated with abnormal coagulation in the setting of intrauterine fetal death (IUFD).

Methods: We reviewed the charts of 238 patients diagnosed with IUFD over ten years. Data included demographics, coexisting obstetric disease and coagulation studies. A coagulation score was assigned based on the platelet count, prothrombin time, activated partial thromboplastin time and plasma fibrinogen concentration. Approximately $90 \%$ of the study population had coagulation scores $<4$. A score of $\geq 4$ was considered abnormal.

Results: Complete coagulation analysis was available in $183 / 238$ patients (77\%) within $24 \mathrm{hr}$ of delivery. One hundred and sixty-four of these $(89.6 \%)$ had a coagulation score $<4$ and 19 had a score $\geq 4(10.4 \%)$. No relationship between the coagulation score and age, parity, gestational age at delivery, and number of days the dead fetus remained in utero was found. A coagulation score $\geq 4$ was associated with the presence of a pregnancy-related disease $(P<0.05)$, notably abruption $(P<0.001)$ and uterine perforation $(P<0.05)$. Four patients without co-existing disease $(3.2 \%)$, had a coagulation score $\geq 4$.

Conclusion: In most pregnancies complicated by fetal demise, the fetus and placenta are delivered within one week of fetal demise. The previously reported severe coagulation disturbances are largely eliminated by early delivery. Our study shows that coagulation abnormalities occur in some patients with uncomplicated IUFDs (3.2\%) and that this number rises in the presence of abruption or uterine perforation.

\section{Key words}

ANAESTHESIA: obstetrical; BLOOD: coagulation, coagulopathy; PREGNANCY: abruption, placenta.

From the Department of Anesthesia and Critical Care, Division of Obstetric Anesthesia, Beth Israel Hospital, Harvard Medical School, 330 Brookline Ave, Boston, MA. 02215.

Address correspondences to: Dr. Andrew Maslow. Accepted for publication August 31, 1996.
Objectif: Cette étude visait à déterminer les facteurs associés à une coagulation anormale dans un contexte de mortalité foetale in utero (MFIU).

Méthodes: Les auteurs ont relevé les dossiers de 238 patientes porteuses d'un diagnostic de MFIU sur une période de dix ans. Les données incluaient la démographie, les affections obstétricales associées et le bilan hémostatique. Un score de coagulabilité a été assigné d'après le décompte plaquettaire le temps de prothrombine, le temps de thromboplastine par. tielle activé et la concentration plasmatique du fibrinogène. Environ $90 \%$ de la population étudiée avait un score de coagulabilité <4. Un score $\geq 4$ était considéré comme anormal. Résultats: Un bilan hémostatique était disponible chez 183/238 patientes (77\%) à $24 \mathrm{~h}$ de l'accouchement. De ces patientes, I64 $(89,6 \%)$ avaient un score de coagulabilité $<4$, et 19 avaient un score $\geq 4(10,4 \%)$. On n'a pas trouvé de rapport entre le score de coagulabilité et l'âge, la parité, l'âge gestationel à l'accouchement et la durée de présence du foetus mort in utero. Un score de coagulabilité $\geq 4$ était associé à une maladie de la grossesse $(P<0,05)$, notamment à un décollement placentaire $(P<0,00 I)$ ou à perforation utérine $(P<$ $0,05)$. Quatre patientes sans maladies obstétricales associées $(3,2 \%)$ avaient un score de coagulabilité $\geq 4$.

Conclusion: La plupart des grossesses compliquées par une mort foetale expulsent le foetus et le placenta dans le semaine qui suit la mort du foetus. Les dérangements graves de la coagulation rapportés antérieurement sont en grande partie éliminés par un accouchement précoce. Notre étude montre que les anomalies de la coagulation surviennent chez certaines patientes avec une $M F I U(3,2 \%)$ et que ce nombre augmente en présence d'un décollement placentaire ou d'une perforation utérine.

Intrauterine fetal death (IUFD) occurs in $<1 \%$ of singleton pregnancies. ${ }^{1}$ The incidence in twin pregnancies varies between 0.5 and $6.8 \%{ }^{2}$ A link between coagulopathy and IUFD was first reported in $1950 .{ }^{3}$ This concept was expanded and the term Dead Fetus Syndrome was coined to describe a pregnancy complicated with an IUFD and a plasma fibrinogen concentration $<150$ $\mathrm{mg} \cdot \mathrm{dl}^{-1} .4$ The occurrence of hypofibrinogenaemia in 
parturients diagnosed with IUFD ranges from $0-10 \%$ at initial presentation. The incidence may reach $40 \%$ if the fetal and placental tissues remain in utero longer than five weeks. ${ }^{5,6}$

In the past, women with IUFDs were managed expectantly and approximately $90 \%$ began spontaneous labour within three weeks of fetal death. ${ }^{7}$ Current practice is to induce labour earlier both because many women do not wish the dead fetus to remain in utero for weeks and because of the possibility of developing a coagulopathy. For early pregnancies, dilatation of the cervix and evacuation of the uterus have been used. ${ }^{8,9}$

The purpose of this study was to determine what factors were associated with abnormal coagulation in women with IUFD, and to determine if delivery within days of fetal demise (current practice) led to an absence of coagulation changes in these women.

\section{Methods}

After approval by the Hospital Committee on Investigation, the charts of patients admitted with a diagnosis of IUFD were reviewed for the period 1984-1994. Intrauterine fetal death was defined as a dead fetus at $\geq 24$ wk gestational age based on the likelihood of survival beyond 24 wk compared with survival at $<24$ wk. ${ }^{10}$ Data collected included age, parity, gestational age at delivery, number of days of retained deal fetal tissue (days IUFD), method of delivery, year of delivery, pregnancy-related diagnosis, coagulation studies within $24 \mathrm{hr}$ before delivery, and administration of blood products. A complete set of coagulation studies included platelet count, prothrombin time (PT), activated partial thromboplastin time (aPTT) and plasma fibrinogen concentration. The pregnancy-related diagnoses sought included abruptio placentae, pregnancy induced hypertension (PIH), placenta praevia, gestational diabetes mellitus, previous IUFD, chorioamnionitis, vasa praevia and uterine perforation.

Differences in coagulation scores were determined by analysis of variance (ANOVA). Hypothesis tests on tabular data were performed using Chi square analysis. The S-PLUS v3.3 software package was used for analysis (Statistical Sciences, Seattle, WA).

\section{Results}

The charts of 238 patients were reviewed. Two hundred and twelve $(89 \%)$ were delivered vaginally and 26 (11\%) by Caesarean section. There were 218 singleton pregnancies $(91.6 \%)$. Twenty were multiple gestation pregnancies with at least one remaining live fetus.

A coagulation score was developed to assist with statistical analysis (Table I). A full set of coagulation studies (platelet count, PT, aPTT and plasma fibrinogen
TABLE I Coagulation scoring

\begin{tabular}{lll}
\hline Test & Laboratory result & Points \\
\hline Platelets & $>125 \mathrm{~K}$ & 0 \\
$\left(100 \mathrm{~K} \cdot \mathrm{ml}^{-3}\right)$ & $100-125$ & 1 \\
& $80-<100$ & 2 \\
& 80 & 3 \\
Prothrombin & $<1.1$ & 0 \\
Time (PT) & $1.1-1.2$ & 1 \\
patient:control & $>1.2-1.5$ & 3 \\
& $>1.5$ & 5 \\
Partial & $<1.1$ & 0 \\
Thromboplastin & $1.1-1.2$ & 1 \\
Time (PTT) & $>1.2-1.5$ & 3 \\
patient:control & $>1.5$ & 5 \\
Fibrinogen & $>350$ & 0 \\
(mg $\cdot \mathrm{dl}^{-1}$ ) & $300-350$ & 1 \\
& $250-<300$ & 2 \\
& $200-<250$ & 3 \\
& $150-<200$ & 4 \\
& $<150$ & 5 \\
\hline
\end{tabular}

The above point schedule is applied to the individual laboratory values. The total number of points is added to give the coagulation score.

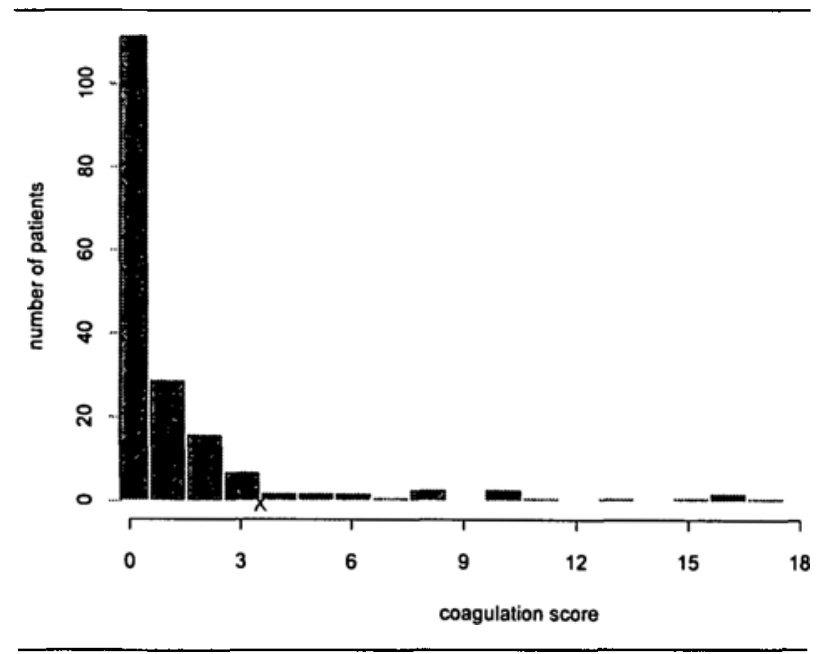

FIGURE I Histogram showing the distribution of coagulation scores in 183 patients with the diagnosis of IUFD.

concentration) was obtained in 183 patients (77\%) within $24 \mathrm{hr}$ of delivery. One hundred and sixty-four patients (89.6\%) had a coagulation score $<4$ and $19(10.4 \%)$ patients scored $\geq 4$. An abnormal score was defined as $\geq 4$ (Figure 1).

One hundred and twenty-four of these patients $(68 \%)$ had no pregnancy-related diagnosis. The diagnosis of the patients with pregnancy-related diagnoses are summarized in Table II. There were no relationships between coagulation score and age, parity, gestational age at delivery, number of days with IUFD, method of delivery or type of anaesthesia received. Coagulation 
TABLE II Number of patients by diagnoses with a coagulation score $\geq 4$

\begin{tabular}{lll}
\hline Diagnosis & $\begin{array}{l}\text { Number of patients } \\
\text { with diagnosis }\end{array}$ & $\begin{array}{l}\text { Number of patients with } \\
\text { COAG } \geq 4 \text { (scores) }\end{array}$ \\
\hline None & 124 & $4(5,5,8,13)$ \\
PIH (only) & 17 & 0 \\
Abruption (only) & 14 & $7(4,7,10,10,15,16,16)$ \\
Chorioamnionitis & 10 & 0 \\
Abruption/PIH & 6 & $5(6,6,8,11,17)$ \\
Gestational DM & 3 & 0 \\
Previous IUFD & 3 & $1(10)$ \\
Uterine Perforation & 2 & $2(4,8)$ \\
Placenta PrAevia & 2 & 0 \\
Vasa Praevia & 2 & 0 \\
Total & 183 & 19 \\
\hline
\end{tabular}

scores $\geq 4$ were associated with pregnancy-related diagnoses $(P<0.05)$, particularly placental abruption $(P<$ $0.001)$ and uterine perforation $(P<0.05)$. Included in the 19 patients with a coagulation score $\geq 4$ were 12 patients with abruptio placentae (five with PIH, seven without), two women with uterine perforation and one patient with a previous IUFD. Of the 124 patients without pregnancy-related diagnoses, four $(3.2 \%)$ had coagulation scores $\geq 4$. All were single gestation pregnancies and delivered within $24 \mathrm{hr}$ of the diagnosis of IUFD. There was no evidence of retained placentae in any of the four patients.

Of the nineteen patients with coagulation score $\geq 4$, five had abnormalities in all four tests, seven were abnormal in three tests, five were abnormal in two test, and two were abnormal in only one test. The two patients in which there was only one abnormality had fibrinogen concentrations less than $150 \mathrm{mg} \cdot \mathrm{dl}^{-1}$.

Sensitivities, specificities, and predictive values for the four laboratory tests of coagulation are shown in Table III. All four tests had high predictive negative values. A fibrinogen concentration $>350 \mathrm{mg} \cdot \mathrm{dl}^{-1}$ had a $100 \%$ predictive negative value. Only a PT to 1.1 times control and a platelet count of $\leq 100,000 \cdot \mathrm{ml}^{-3}$ had high predictive positive values (100\% and $91 \%$ respectively). With the exception of the fibrinogen concentration, all tests had high specificities while only the fibrinogen concentration had a high sensitivity.

According to our scoring system, 15 of the 19 patients with a coagulation score $\geq 4$ had an abnormal platelet count i.e., $\leq 125,000 \cdot \mathrm{ml}^{-3}(104,000 \pm$ $\left.45,000 \cdot \mathrm{ml}^{-3}\right)$. Of the 164 patients with coagulation score $<4$ (mean 234,000 $\pm 64,000 \cdot \mathrm{ml}^{-3}$ ), six had platelet counts $<125,000 \cdot \mathrm{ml}^{-3}\left(81,000-124,000 \cdot \mathrm{ml}^{-3}\right)$. If a platelet count of $\leq 100,000 \cdot \mathrm{ml}^{-3}$ was considered abnormal, then only one patient with coagulation score $<4$ had a low platelet count $\left(81,000 \cdot \mathrm{ml}^{-3}\right)$.
TABLE III Sensitivities, specificities, predicted positve (PPV) and negative (PNV) values for individual laboratory tests. Abnormal coag score is defined as $\geq 4$.

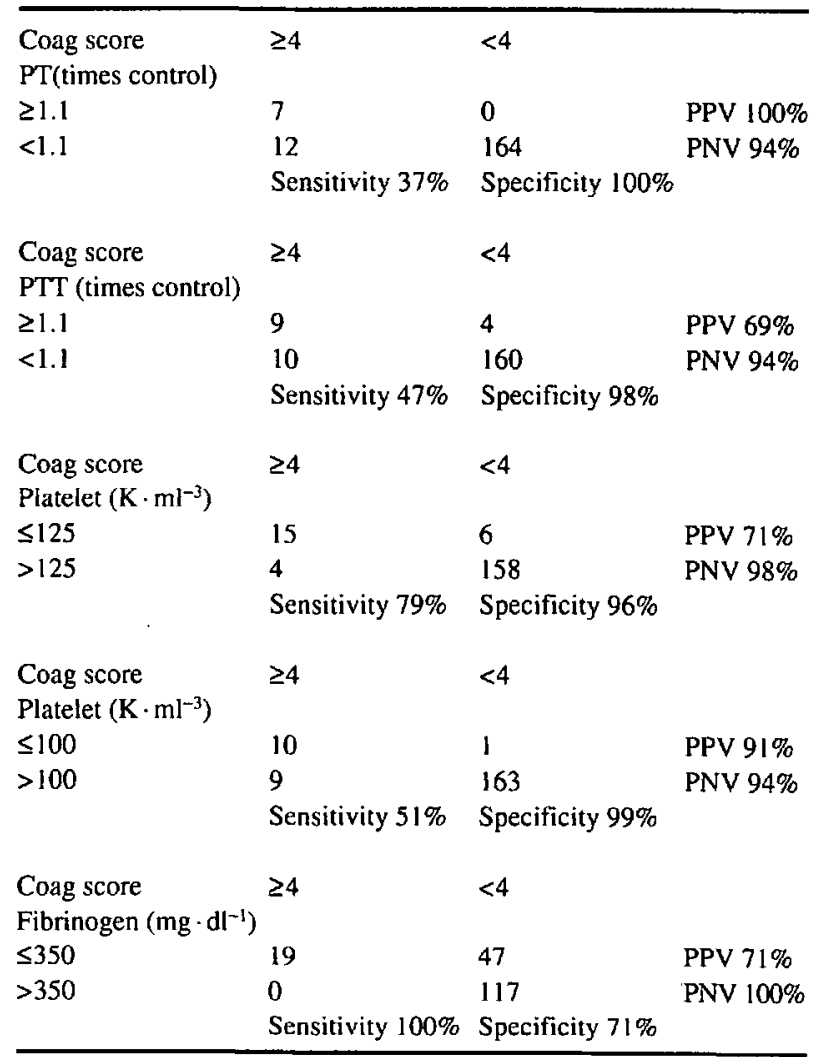

Sensitivities, specificities, and predictive positive and negative values are shown for the four laboratory tests of coagulation. Abnormal coag score is defined as $\geq 4$. There are two analyses for platelet count; the first using $>125 \mathrm{~K} \cdot \mathrm{ml}^{-3}$ as normal and the second using $>100 \mathrm{~K} \cdot \mathrm{ml}^{-3}$ as abnormal. All tests except fibrinogen showed a high specificity while only fibrinogen showed a high sensitivity. Ali tests showed high predictive negative values while only PT $\geq 1.1 \mathrm{sec}$ and platelet count $\leq 100 \mathrm{~K} \cdot \mathrm{ml}^{-3}$ had high predictive positive values.

Fifty-five patients did not have a complete coagulation profile performed. Sixteen of these patients had no coagulation studies performed and 17 had only platelet counts performed, all of which were $>125,000 \cdot \mathrm{ml}^{-3}$. There were four abnormal laboratory values (two fibrinogen concentrations; 324 and $325 \mathrm{mg} \cdot \mathrm{dl}^{-1}$, and two aPTT 35.7 and $35.9 \mathrm{sec}$ ) occurring in four patients. According to the scoring table, these values would have resulted in one point each.

There were six patients with a coagulation score of 3 . Three of these patients, one with PIH, one with placenta praevia, and one without a pregnancy related diagnosis, had fibrinogen concentration between 200 and 250 $\mathrm{mg} \cdot \mathrm{dl}^{-1}(200,217,245)$. A fourth patient (without a pregnancy related diagnosis) had a fibrinogen concen- 
tration of $251 \mathrm{mg} \cdot \mathrm{dl}^{-1}$ and platelet count of 114,000 platelets $\cdot \mathrm{ml}^{-3}$. A fifth patient without a pregnancy related diagnosis had a platelet count of 81,000 platelets $\cdot \mathrm{ml}^{-3}$ and fibrinogen of $327 \mathrm{mg} \cdot \mathrm{dl}^{-1}$. The sixth patient had chorioamnionitis and a PTT of $37 \mathrm{sec}$. The percentage of patients, without a pregnancy related diagnosis, with an abnormal coagulation score would increase from $3.2 \%$ to $5.6 \%$ if a coagulation score of $\geq 3$ or greater was considered abnormal.

Only eight patients carried a singleton gestation dead fetus more than seven days. Seven of these women had coagulation scores $<3$ and the other a score $=3$. This patient developed chorioamnionitis and had an aPTT of $37 \mathrm{sec}$.

Of the charts reviewed, 218 pregnancies were single gestation and 20 multiple gestation. Coagulation scores were calculated on 168 and 15 patients respectively. The mean number of days with retained dead fetal tissue and coagulation scores (mean, range) in singleton pregnancies were 2.4 days and $1.5(0-17)$. For multiple gestation pregnancies, the corresponding values were 23.4 days and $0.4(0-2)$. In the multiple gestation group, 11 patients had a coagulation score of 0 , two had a score of 1 , and two had a score of 2.

Fourteen patients in the study received blood products. Ten of these women had coagulation scores $\geq 4$, one had a score of 2 , and two patients a score of 0 . The other patient had a normal PT, aPTT and platelet count; plasma fibrinogen concentration was not measured. Three of these 14 women did not have any pregnancy related disease as listed in Table II. Two of these three had retained placental tissue requiring manual removal. These two women received packed red blood cells on the basis of a low hematocrit. Overall, patients receiving blood products had a mean coagulation score of 8.2 compared with 0.9 for those not receiving blood products.

\section{Discussion}

This study demonstrates, in patients with IUFD, a relationship between abnormal coagulation score and the presence of certain pregnancy-related conditions. The most important associated diseases were uterine perforation and abruption (with or without PIH). However, $3.2 \%$ of patients without a pregnancy-related diagnosis developed abnormal coagulation scores as defined in the study. None of the eight patients with singleton pregnancies and retained fetal tissue for 7-21 days developed coagulation scores $\geq 4$. Because of the small sample size and lack of prolonged pregnancy with retained fetal tissue, we cannot draw any conclusions in this group. Earlier studies demonstrated a relationship between the duration of retained dead fetal tissue and abnormal coagulation where coagulopathies occurred and worsened beyond four weeks after fetal demise. ${ }^{5,6}$

Coagulation changes during and after pregnancy have been well documented. There is an increase in procoagulant factor activity with plasma fibrinogen concentrations being invariably $>300 \mathrm{mg} \cdot \mathrm{dl}^{-1}$ (usually $400-650$ $\mathrm{mg} \cdot \mathrm{dl}^{-1}$ ) compared with concentrations in non-pregnant women of $200-400 \mathrm{mg} \cdot \mathrm{dl}^{-1} \cdot{ }^{11-15}$ Active fibrinolysis during the third trimester and labour is suggested by fibrin degradation products of $10-40 \mu \mathrm{g} \cdot \mathrm{ml}^{-1} .{ }^{19}$ Platelet count either does not change or decreases by a small amount during pregnancy. ${ }^{14,18-21}$ Schafer described the coagulation state of pregnancy as low grade, well compensated, intravascular coagulation in which late complications can further activate the clotting system and lead to fulminant disseminated intravascular coagulation (DIC). ${ }^{22}$ These haematological changes are thought to represent normal protective mechanisms against massive haemorrhage after delivery of the fetus and placenta. $^{22,23}$

The diagnosis of DIC is dependent on the clinical picture, laboratory tests, and the absence of confounding factors (vitamin $\mathrm{K}$ deficiency, liver disease, anitcoagulants etc.). Initial screening tests for DIC may include PT, aPTT, platelet count, and fibrinogen concentration. Although abnormalities of all four tests establishes the diagnosis of DIC, often only one, two, or three tests are abnormal. ${ }^{25}$

The mechanism suggested to explain coagulopathy associated with IUFD involves release of tissue thromboplastin from the fetal circulation into the maternal circulation. ${ }^{1,3}$ Thromboplastin is thought to stimulate the maternal coagulation system causing intravascular consumption of clotting factors and platelets. A corresponding increase in activity of the fibrinolytic pathway leads to breakdown of fibrinogen to form fibrin degradation products (FDPs) and fibrin-fibrin dimers (D-dimers).

The relation between abnormal coagulation and pregnancy-related medical diseases is not surprising, especially with abruptio placentae. Disseminated intravascular coagulation is reported in approximately $10 \%$ of women suffering placental abruption with the number rising to as high as $30 \%$ when fetal death occurs. $1,23,26$ Our findings of a high incidence of coagulation abnormalities $(50 \%)$ are consistent with previous work. The combination of abruption, PIH and IUFD was associated with coagulation abnormalities in $83 \%$ of pregnancies.

Clinically important coagulopathy occurs with eclampsia and preeclampsia with an incidence of $9.1 \%$ and $2.6 \%$ respectively. ${ }^{26}$ The most common abnormality is thrombocytopenia. In our study one of 17 patients (6\%) with PIH alone had a coagulation score $=3$, while 


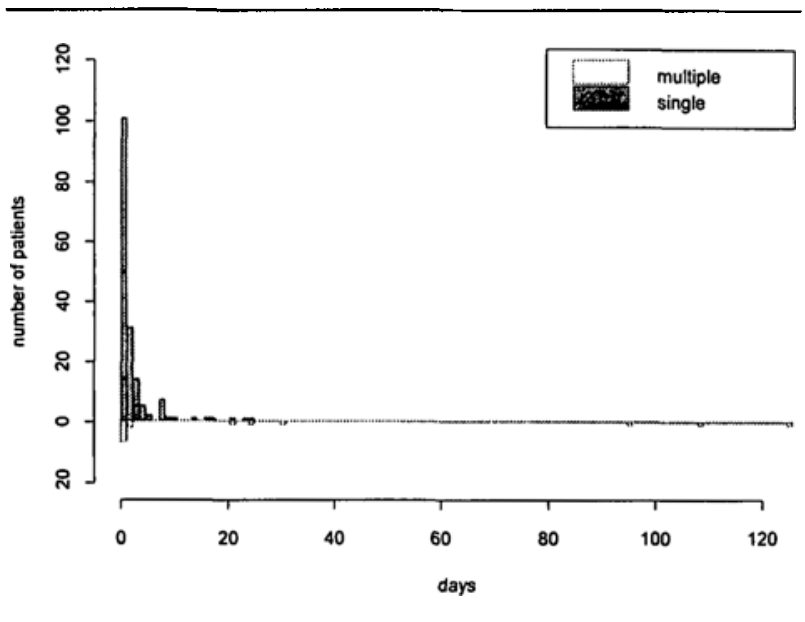

FIGURE 2 Distribution of dIUFD among single gestation pregnancies (above the " $x$ " axis) and among multiple gestation (below the " $x$ " axis).

five of six (83\%) patients with PIH and abruption had a coagulation score of $\geq 4$.

Uterine perforation is an uncommon complication of pregnancy and associated with a maternal mortality of $0.1 \% .^{27}$ Spontaneous uterine perforation is a suspected cause of DIC in the pregnant patient. ${ }^{28}$ In these patients, mortality due to haemorrhage may be as high as $66 \%$ if the diagnosis is not suspected or if haemotherapy is not adequate. ${ }^{27,28}$ Both cases, in our series, of spontaneous uterine perforation had abnormal coagulation scores (>4).

In our study we did not see coagulation changes in those women with multiple gestation and IUFD. This might be considered surprising as clinical management in these cases is to continue the pregnancy to enhance development of the remaining viable fetus(es) while being aware of the possible development of a coagulopathy. We found the coagulation score did not increase as pregnancy continued for three weeks following demise of one fetus. Indeed, we found a lower coagulation score in our multiple gestation patients despite a longer mean duration of IUFD (Figure 2). A literature review from 1989 found 12 cases of multiple gestation pregnancy managed expectantly for 2-12 wk after demise of one fetus. ${ }^{29}$ Three women $(25 \%)$ developed DIC and were successfully managed with subcutaneous or intravenous heparin to allow the pregnancy to continue. The women were delivered when the fetus(es) were 35-37 wk gestational age. Some authors suggest that the surviving fetus and placenta act as a "siphon and/or sieve for the thromboplastic substance" preventing access to the maternal circulation and making DIC less common for a given gestational age in the setting of IUFD and multiple gestation. ${ }^{2}$

\section{Limitations}

There are a number of limitations to this study. The first is the retrospective nature of data collection. We had no control of what coagulation tests were measured and when they were ordered. Because of this, $24 \%$ of the charts reviewed did not have complete sets of coagulation studies by our definition. In part, this may be a reflection of obstetrical practice with delivery soon after fetal demise and the low incidence of coagulation changes at this time.

The constructed coagulation score may also be a limitation. The assignment of points was designed to facilitate statistical comparison. The coagulation score is not based on clinical outcome and has not been applied prospectively. Studies quantifying coagulation abnormalities in pregnant women are limited. The scoring system was based on review of the literature concerning pregnant patients and also the cardiology literature. ${ }^{30-32}$ A scale of 0-5 was used for plasma fibrinogen concentrations based on the large range of data points. Less weight was given to platelet count $(0-3)$, as the number that is "abnormal" is not clearly defined. ${ }^{18-21}$ The range describing a normal platelet count at our hospital is 150,000 to $300,000 \cdot \mathrm{ml}^{-3}$. As the platelet count may decrease in normal pregnancy, we assigned $125,000 \cdot \mathrm{ml}^{-3}$ as abnormal in our study. If we assumed that third trimester gestational thrombocytopenia resulted in lower platelet counts $\left(<125,000 \cdot \mathrm{ml}^{-3}\right)$ and changed our scoring system in accordance $\left(\geq 80,000 \cdot \mathrm{ml}^{-3}=\right.$ normal; $70-79,000 \cdot \mathrm{ml}^{-3}=1$; $60-69,000 \cdot \mathrm{ml}^{-3}=2$; and $<60,000 \cdot \mathrm{ml}^{-3}=3$ ) then two patients would change from an abnormal coagulation score to a normal score resulting in no change in results. Of the patients with coagulation score $\geq 4$ there were three patients with second trimester IUFD and their platelet counts were $170,000 \cdot \mathrm{ml}^{-3}$ (coagulation score $=$ 5), $109,000 \cdot \mathrm{ml}^{-3}$ (coagulation score $=8$ ), and $66,000 \cdot \mathrm{ml}^{-3}$ (coagulation score $=10$ ). The gradation of the prothrombin time was based on anticoagulation of patients with atrial fibrillation where the goal is generally a PT of 1.2 to 1.5 times control. ${ }^{30-33}$ These studies found that a PT of 1.2-1.5 times control was therapeutic and that when the PT was $>1.5$ times control bleeding complications were more common. A PT $<1.2$ times control was equivalent to placebo. A PT of 1.2-1.5 times control is equivalent to an International Normalized Ratio (INR) of 2.0 to 3.0, the range generally recommended for management of deep venous thrombosis, pulmonary embolism and for prevention of systemic embolization. ${ }^{33}$ Since a PT $>1.5$ times control 
is anticoagulated we assigned five points, a PT of 1.2 to 1.5 times control is therapeutic so we assigned three points and a normal PT is not associated with bleeding so we assigned 0 points. We assigned one point to a PT of 1.1 to 1.2 times control as it is in between. A similar line of reasoning was used when assigning points based on the aPTT. ${ }^{34}$

The change from normal coagulation to severe DIC is along a continuum. Coagulation changes, not DIC, were defined in terms of a coagulation score. The cut-off point of 4 was chosen to identify the $10 \%$ of women having this degree of abnormality and to facilitate comparison of this group with the others in the study. The amount of bleeding that occurred would be valuable information but it was not recorded accurately. Blood products were administered to $53 \%$ of patients with coagulation scores $\geq 4$ compared with $2.4 \%$ of the remaining patients. Although a relation between coagulation score and administration of blood products is suggested, it is difficult to draw conclusions, particularly since transfusion practices have changed markedly over the time of the study.

\section{Conclusion}

While, in current practice, women with IUFD are usually delivered within days of the diagnosis, there is a small risk of coagulation abnormalities. This risk is higher when IUFD is combined with uterine perforation, placental abruption or abruption plus PIH. In multiple gestations with loss of a fetus, the risk of coagulation changes appears to be lower. We recommend that coagulation studies be considered in the presence of IUFD, particularly when combined with uterine perforation, abruption or abruption plus PIH. While a full coagulation profile may be more informative and better establish the diagnosis of DIC, it may be reasonable to measure a prothrombin time and/or fibrinogen concentration as screening tests given the high predictive values found in this study, and high sensitivity of an abnormal fibrinogen concentration (using $\leq 350 \mathrm{mg} \cdot \mathrm{dl}^{-1}$ as abnormal) and high specificity found with a normal prothrombin time.

\section{References}

1 Finley BE. Acute coagulopathy in pregnancy. Med Clin North Am 1989; 73: 723-43.

2 Dudley $D K L, D^{\prime}$ Alton $M E$. Single fetal death in twin gestation. Semin Perinatol 1986; 10: 65-72.

3 Weiner AE, Reid DE, Roby CC, Diamond LK. Coagulation defects with intrauterine death from $\mathrm{Rh}$ isosensitization. Am J Obstet Gynecol 1950; 60: 1015-22.

4 Von Hugo R, Graeff $H$. Thrombohemorrhagic complicatjons in the obstetric patient. In: Colman RW, Hirsh J,
Marder VJ, Salzman EW (Eds.). Hemostasis and Thrombosis: Basic Principles and Clinical Practice, 2nd ed. Philadelphia: JB Lippincott, 1987: 926-41.

5 Phillips $L L$, Skrodelis V, King TA. Hypofibrinogenemia and intrauterine fetal death. Am J Obstet Gynecol 1964; 89: 903-14.

6 Pritchard JA. Fetal death in utero. Obstet Gynecol 1959; 14: 573-80.

7 Tricomi V, Kohl SG. Fetal death in utero. Am J Obstet Gynecol 1957; 74: 1092-7.

8 Schulman H, Saldana L, Lin C-C, Randolph G. Mechanism of failed labor after fetal death and its treatment with prostaglandin $\mathrm{E}_{2}$. Am J Obstet 1979; 133: 742-52.

9 Bailey $C D H$, Newman $C$, Ellinas $S P$, Anderson $G G$. Use of prostaglandin $\mathrm{E}_{2}$ vaginal suppositories in intrauterine fetal death and missed abortion. Obstet Gynecol 1975; 44: 110-3.

10 Allen MC, Donohue PK, Dusman AE. The limit of viability-neonatal outcome of infants born at 22 to 25 weeks' gestation. N Eng J Med 1993; 329: 1597-601.

11 Gjønnass $H$, Fagerhol MK. Studies on coagulation and fibrinolysis in pregnancy. With special reference to cold activation of factor VII. Acta Obstet Gynecol Scand 1975; 54: 363-7.

12 Hellgren $M$, Blombäck $M$. Studies on blood coagulation and fibrinolysis in pregnancy, during delivery and in the puerperium. I. Normal conditions. Gynecol Obstet Invest 1981; 12: 141-54.

13 Cheek TG, Gutsche BB. Maternal physiologic alterations during pregnancy. In: Shnider S, Levinson G (Eds.). Anesthesia for Obstetrics, 3rd ed. Baltimore MD: Williams and Wilkins, 1993: 3-17.

14 Beller $F K$, Ebert $C$. The coagulation and fibrinolytic enzyme system in pregnancy and in the puerperium. Eur $\mathbf{J}$ Obstet Gynecol Reprod Biol 1982; 13: 177-97.

15 Nilsson $I M$, Kullender $S$. Coagulation and fibrinolytic studies during pregnancy. Acta Obstet Gynecol Scand 1967; 46: 273-85.

16 Âstedt B. Fibrinolytic activity during labour. Acta Obstet Gynecol Scand 1972; 51: 171-4.

17 Müller-Berghaus G, Moeller R-M, Mahn I. Fibrinogen turnover in pregnant rabbits during the first and last thirds of gestation. Am J Obstet Gynecol 1978; 131: 655-60.

18 Burrows $R F$, Kelton $J G$. Incidentally detected thrombocytopenia in healthy mothers and their infants. N Eng J Med 1988; 319: 142-5.

19 O'Brien WF, Saba HI, Knuppel RA, Scerbo JC, Cohen GR. Alterations in platelet concentration and aggregation in normal pregnancy and preeclampsia. Am J Obstet Gynecol 1986; 155: 486-90.

20 Fenton V, Saunders $K$, Cavill 1 . The platelet count in pregnancy. J Clin Pathol 1977; 30: 68-9.

21 Fay RA, Hughes AO, Farron NT. Platelets in pregnancy: 
hyperdestruction in pregnancy. Obstet Gynecol 1983; 61:

238-40.

22 Schafer AI. The hypercoagulable states. Ann Intern Med 1985; 102: 814-28.

23 Mayer DC. Hemorrhagic obstetric emergencies. Seminars in Anesthesia 1992; 11:32-42.

24 Camann WR, Ostheimer GW. Physiological adaptions during pregnancy. Int Anesthesiol Clin 1990; 28: 2-10.

25 Schmaier $A H$. Disseminated intravascular coagulation: pathogenesis and management. Journal of Intensive Care Medicine 1991;6:209-28.

26 Lester EP, Roth DG. Disseminated intravascular coagulation in pregnancy. J Reprod Med 1977; 19: 223-32.

27 Megafu $U$. Factors influencing maternal survival in ruptured uterus. Int J Gynecol Obstet 1985; 23: 475-80.

28 Ware HH Jr. Rupture of the uterus. Clin Obstet Gynecol 1960; 3: 637-45.

29 Landy $H J$, Weingold $A B$. Management of a multiple gestation complicated by an antepartum fetal demise. Obstet Gynecol Surv 1989; 44: 171-6.

30 European Atrial Fibrillation Trial Study Group. Optimal oral anticoagulation therapy in patients with nonrheumatic atrial fibrillation and recent cerebral ischemia. $N$ Eng $J$ Med 1995; 333: 5-10.

31 Dunn $M$, Alexander J, de Silva R, Hildner $F$. Antithrombotic therapy in atrial fibrillation. Chest 1986; 89: 68S-74

32 Hirsh J, Deykin D, Poller L. "Therapeutic range" for oral anticoagulant therapy. Chest 1986; 89: 11S-5.

33 Hirsh J, Fuster V. Guide to anticoagulant therapy. Part 2: oral anticoagulants. Circulation 1994; 89: 1469-80.

34 Hirsh J, Fuster V. Guide to anticoagulant therapy. Part 1: heparin. Circulation 1994; 89: 1449-68. 